\title{
Morphology and evolutionary significance of the atlas-axis complex in varanopid synapsids
}

\author{
Nicolás E. Campione and Robert R. Reisz \\ Acta Palaeontologica Polonica 56 (4), 2011: 739-748 doi: http://dx.doi.org/10.4202/app.2010.0071
}

The atlas-axis complex has been described in few Palaeozoic taxa, with little effort being placed on examining variation of this structure within a small clade. Most varanopids, members of a clade of gracile synapsid predators, have well preserved atlas-axes permitting detailed descriptions and examination of morphological variation. This study indicates that the size of the transverse processes on the axis and the shape of the axial neural spine vary among members of this clade. In particular, the small mycterosaurine varanopids possess small transverse processes that point posteroventrally, and the axial spine is dorsoventrally short, with a flattened dorsal margin in lateral view. The larger varanodontine varanopids have large transverse processes with a broad base, and a much taller axial spine with a rounded dorsal margin in lateral view. Based on outgroup comparisons, the morphology exhibited by the transverse processes is interpreted as derived in varanodontines, whereas the morphology of the axial spine is derived in mycterosaurines. The axial spine anatomy of Middle Permian South African varanopids is reviewed and our interpretation is consistent with the hypothesis that at least two varanopid taxa are present in South Africa, a region overwhelmingly dominated by therapsid synapsids and parareptiles.

Key words: Synapsida, Varanopidae, Mycterosaurinae, Varanodontinae, atlas-axis complex, axial skeleton, Middle Permian, South Africa.

Nicolás E. Campione [nicolas.campione@ utoronto.ca], University of Toronto, Department of Ecology and Evolutionary Biology, 100 Queen's Park, Toronto, Ontario, Canada M5S 2C6; Robert R. Reisz [robert.reisz@ utoronto.ca], University of Toronto Mississauga, Department of Biology, 3359 Mississauga Rd. N., Mississauga, Ontario, Canada L5L 1C6.

This is an open-access article distributed under the terms of the Creative Commons Attribution License (for details please see creativecommons.org), which permits unrestricted use, distribution, and reproduction in any medium, provided the original author and source are credited. 
FoF Full text $(1,841.8 \mathrm{kB})$ 